\title{
Correlated Measurements Of Free And Total Intracellular Calcium
}

\author{
S.B. Andrews, * N.B. Pivovarova, * J. Hongpaisan, * C.A. Brantner* and R.D. Leapman** \\ *Laboratory of Neurobiology, NINDS, and ** Division of Bioengineering and Physical Science, \\ ORS, NIH, Bethesda, MD 20892.
}

Transient changes in the intracellular distribution of calcium ions act as a trigger for a large number of important physiological functions [1,2]. The nature of intracellular $\mathrm{Ca}$ changes is complex, however, because $\mathrm{Ca}$ is dynamically distributed between several compartments, the most important being the cytosol, mitochondria and the endoplasmic reticulum (ER). Within each compartment, $\mathrm{Ca}$ is further partitioned between a large pool bound to buffers (mainly proteins) and a much smaller pool of "free $\mathrm{Ca}^{2+}$." Although small, concentration changes in the latter pools, especially cytosolic free $\mathrm{Ca}^{2+}\left(\left[\mathrm{Ca}^{2+}\right]_{i}\right)$, are especially critical for signal transduction. To obtain a general picture of the interactions and spatio-temporal concentration fluctuations that underlie $\mathrm{Ca}^{2+}$ signaling, correlated measurements of both free and bound $\mathrm{Ca}$ pools are highly advantageous [3]. Optical imaging of fluorescent indicators in living cells is the method of choice for measuring $\left[\mathrm{Ca}^{2+}\right]_{\mathrm{i}}$, while analytical electron microscopy - either electron probe x-ray microanalysis (EPMA) or electron energy loss spectroscopy (EELS) - is the well established approach for determining total $\mathrm{Ca}$ (essentially equivalent to bound $\mathrm{Ca}$ ) within specific subcellular compartments. When these techniques are used in tandem, the combined information provides unique insights into the regulation of $\mathrm{Ca}^{2+}$ signaling. To illustrate the kinds of information available with this approach, we present here results from recent work aimed at elucidating the role of mitochondrial and $\mathrm{ER} \mathrm{Ca}^{2+}$ transport in the modulation of $\mathrm{Ca}^{2+}$ signaling in neurons.

Our first example explores the role of mitochondrial $\mathrm{Ca}^{2+}$ uptake in blunting the impact of depolarization-induced $\mathrm{Ca}^{2+}$ entry on the signaling $\mathrm{Ca}^{2+}$ pool, i.e., on $\left[\mathrm{Ca}^{2+}\right]_{i}[4,5]$. Optical measurements (fura-2) show that sympathetic neurons respond to depolarization with a rise in $\left[\mathrm{Ca}^{2+}\right]_{i}$ that has several prominent phases (Fig. 1, upper panel). Following a sharp initial rise, $\left[\mathrm{Ca}^{2+}\right]_{\mathrm{i}}$ is clamped at a steady elevated concentration $(\sim 750 \mathrm{nM}$ for a depolarization to $\sim 0 \mathrm{mV})$ for the duration of the stimuli $(<2 \mathrm{~min})$, even though $\mathrm{Ca}^{2+}$ entry continues; upon repolarization (which closes membrane channels and stops $\mathrm{Ca}^{2+}$ influx $),\left[\mathrm{Ca}^{2+}\right]_{i}$ recovers only slowly, exhibiting a plateau phase $\left(\left[\mathrm{Ca}^{2+}\right]_{\mathrm{i}}\right.$ $\sim 400 \mathrm{nM}$ ) of several minutes duration (arrow). The explanation for this complex behavior is revealed by parallel EMPA measurements of mitochondrial total calcium ([Ca $]_{\mathrm{MT}}$ ) (Fig. 1, lower panel), which show that: 1) continuous $\mathrm{Ca}^{2+}$ uptake by mitochondria during sustained stimulation targets entering $\mathrm{Ca}^{2+}$ directly into mitochondria, thereby accounting for the blunted rise and clamped phase of $\left[\mathrm{Ca}^{2+}\right]_{i}$; and 2) subsequent release of the accumulated mitochondrial $\mathrm{Ca}$ load, at a rate determined by the responsible transporters and of a length determined by the size of the load, underlies the delayed $\left[\mathrm{Ca}^{2+}\right]_{\mathrm{i}}$ recovery.

During the recovery phase, ER $\mathrm{Ca}^{2+}$ transport also comes into play [6]. EPMA data on total ER Ca concentrations $\left([\mathrm{Ca}]_{\mathrm{ER}}\right)$, indicate that $[\mathrm{Ca}]_{\mathrm{ER}}$, which changes little during depolarization, rises during $\left[\mathrm{Ca}^{2+}\right]_{\mathrm{i}}$ recovery, as Ca that was formerly part of the mitochondrial $\mathrm{Ca}$ load is transferred into the ER. This observation illustrates one face of the dual nature of $\mathrm{ER} \mathrm{Ca}^{2+}$ handling, namely, its role as a $\mathrm{Ca}$ sink. Perhaps more commonly, the ER is viewed as a $\mathrm{Ca}$ source, responding to agonists like inositol trisphosphate $\left(\mathrm{IP}_{3}\right)$ or $\mathrm{Ca}^{2+}$ itself with $\mathrm{Ca}^{2+}$ release from preloaded stores [2]. This face of ER function can also be revealed by correlated free and total $\mathrm{Ca}$ analyses. Thus, EMPA shows that in resting neurons, the highest $\mathrm{Ca}$ concentration is found in the ER, as would be predicted for a $\mathrm{Ca}$ store (Fig. 2) [6]. Following treatments that discharge this store, for example by inhibiting the uptake pump (thapsigargin) or by opening the $\mathrm{ER} \mathrm{Ca}^{2+}$ release channel (caffeine/ryanodine), [Ca] $]_{\mathrm{ER}}$ falls dramatically (Fig. 2), in conjunction with a cytosolic $\left[\mathrm{Ca}^{2+}\right]_{i}$ transient. It is interesting to note that the Ca content of "fully discharged" ER is not zero. 
These results are but two examples of the advantages of combining optical imaging of free $\mathrm{Ca}^{2+}$ with organelle-level microanalytical measurements of total $\mathrm{Ca}$. In our view, this approach has general applicability in the field of $\mathrm{Ca}^{2+}$ regulation. For example, it has recently been used to dissect temporal aspects of $\mathrm{Ca}^{2+}$ signaling in synaptically activated hippocampal neurons [7]. These studies also reveal that the propagation of $\mathrm{Ca}^{2+}$ signals has a strong spatial component, driving home the need for spatially resolved measurements in future studies. This in turn point to a future goal for analytical microscopy - the continued development of high-resolution imaging approaches, such as EELS spectrum imaging [8-10].

\section{References}

[1] T. Pozzan et al., Physiol. Rev. 74 (1994) 595.

[2] M.J. Berridge, Neuron 21 (1998) 13.

[3] L.D. Pozzo-Miller et al., Microsc. Res. Tech. 46 (1999) 295.

[4] D.D. Friel \& R.W. Tsien, J. Neurosci. 14 (1994) 4007.

[5] N. Pivovarova et al., J. Neurosci. 19 (1999) 6372.

[6] J. Hongpaisan et al., J. Gen. Physiol. 118 (2001) 101.

[7] N. Pivovarova et al., J. Neurosci. 22 (2002) 10653.

[8] J.L. Lavergne et al., Microsc. Microanal. Microstruct. 3 (1992) 517.

[9] J.A. Hunt et al., Microsc. Microanal. 5 (Suppl. 2) (1999) 616.

[10] Supported by the NIH Intramural Research Program.

\section{1}
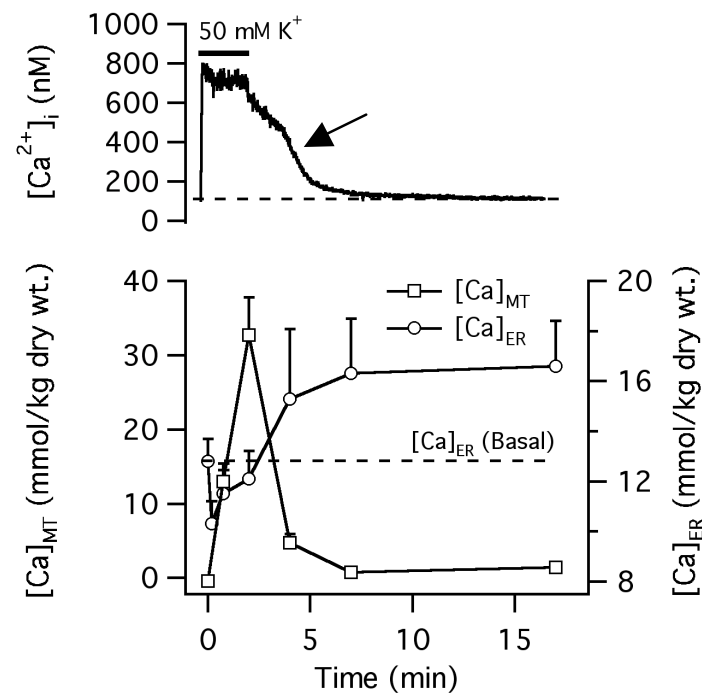

2

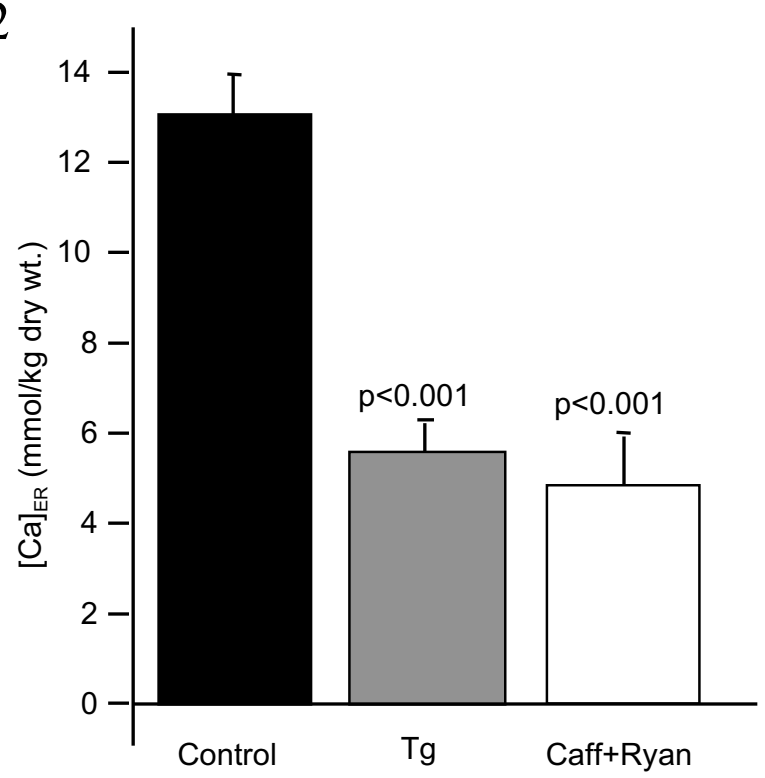

FIG. 1. Comparison between the time courses of $\left[\mathrm{Ca}^{2+}\right]_{\mathrm{i}}$ (top), $[\mathrm{Ca}]_{\mathrm{ER}}$ (circles) and $[\mathrm{Ca}]_{\mathrm{MT}}$ (squares) during a $120 \mathrm{~s}$ exposure to $50 \mathrm{mM} \mathrm{K}^{+}$. Top trace is a representative measurement from a single fura2 loaded sympathetic neuron, while data in lower panel are collected EPMA results from multiple neurons that were stimulated and rapidly frozen at the indicated times.

FIG. 2. The total Ca content of the ER in resting, untreated sympathetic neurons is high (left bar). Inhibition of the ER $\mathrm{Ca}^{2+}$ pump by $1 \mu \mathrm{M}$ thapsigargin $(\mathrm{Tg})$ leads to a large reduction in $[\mathrm{Ca}]_{\mathrm{ER}}$. Similarly, treatments that open the ryanodine receptor (the ER $\mathrm{Ca}^{2+}$ channel; $1 \mu \mathrm{M}$ ryanodine plus $10 \mathrm{mM}$ caffeine) deplete [Ca] $]_{\text {ER }}$ just as effectively. Both drugs induce a transient release of $\mathrm{Ca}^{2+}$ into the cytosol (not shown). 